\title{
Existence of solutions for a system of quasi-variational relation problems and some applications
}

\section{ZHE YANG}

\begin{abstract}
.
In this paper, we study the existence of solutions for a new class of systems of quasi-variational relation problems on different domains. As applications, we obtain existence theorems of solutions for systems of quasi-variational inclusions, systems of quasi-equilibrium problems, systems of generalized maximal element problems, systems of generalized KKM problems and systems of generalized quasi-Nash equilibrium problems on different domains. The results of this paper improve and generalize several known results on variational relation problems.
\end{abstract}

Acknowledgements. Supported by the Chen Guang Project sponsored by the Shanghai Municipal Education Commission and Shanghai Education Development Foundation (no. 13CG35) and open project of Key Laboratory of Mathematical Economics (SUFE), Ministry of Education (no. 201309KF02).

\section{REFERENCES}

[1] Agarwal, R. P., Balaj, M. and O'Regan, D., A Unifying Approach to Variational Relation Problems, J. Optim. Theory Appl., 155 (2012), 417-429

[2] Aliprantis, C. D. and Border, K. C., Infinite Dimensional Analysis: A Hitchhiker's Guide (Third Edition), Springer-Verlag, Berlin Heidelberg, 2006

[3] Balaj, M. and Lin, L. J., Equivalent forms of a generalized KKM theorem and their applications, Nonlinear Anal., $73(2010), 673-682$

[4] Balaj, M. and Lin, L. J., Generalized Variational Relation Problems with Applications, J. Optim. Theory Appl., 148 (2011), 1-13

[5] Balaj, M. and Lin, L. J., Existence Criteria for the Solutions of Two Types of Variational Relation Problems, J. Optim. Theory Appl., 156 (2013), 232-246

[6] Balaj, M. and Luc, D. T., On mixed variational relation problems, Comput. Math. Appl., 60 (2010), 2712-2722

[7] Khanh, P. Q. and Luc, D. T., Stability of solutions in parametric variational relation problems, Set-Valued Anal., 16 (2008), 1015-1035

[8] Lin, L. J. and Ansari, Q. H., Systems of quasi-variational relations with applications, Nonlinear Anal., 72 (2010), $1210-1220$

[9] Lin, L. J. and Wang, S. Y., Simultaneous variational relation problems and related applications, Comput. Math. Appl., 58 (2009), 1711-1721

[10] Luc, D. T., An abstract problem in variational analysis, J. Optim. Theory Appl., 138 (2008), 65-76

[11] Luc, D. T., Sarabi, E. and Soubeyran, A., Existence of solutions in variational relation problems without convexity, J. Math. Anal. Appl., 364 (2010), 544-555

[12] Pu, Y. J. and Yang, Z., Stability of solutions for variational relation problems with applications, Nonlinear Anal., 75 (2012), 1758-1767

[13] $\mathrm{Pu}, \mathrm{Y}$. J. and Yang, Z., Variational relation problem without the KKM property with applications, J. Math. Anal. Appl., 393 (2012), 256-264

[14] Yang, Z. and Pu, Y. J., Generalized Knaster-Kuratowski-Mazurkiewicz Theorem without Convex Hull, J. Optim. Theory Appl., 154 (2012), 17-29

[15] Yang, Z. and Pu, Y. J., Existence and Stability of Solutions for Maximal Element Theorem on Hadamard Manifolds with Applications, Nonlinear Anal., 75 (2012), 516-525

Received: 14.07.2013; In revised form: 08.01.2014; Accepted: 23.04.2014

2010 Mathematics Subject Classification. 49J53, 49J40.

Key words and phrases. System of quasi-variational relations, different domains, variational inclusion. 
SHANGHAI UNIVERSITY OF FINANCE AND ECONOMICS SCHOOL OF ECONOMICS

Key Laboratory of MATHEMATICAl ECONOMICS (SUFE), Ministry OF EDUCATION GUODING STREET No. 777, 200433 SHANGHAI, CHINA

E-mail address: zheyang211@163.com 